RU Полидискурсивность как способ реализации категории интерсемиотичности (на материале прессы Германии и США)

\author{
Коломийцева О. Ю.
}

\begin{abstract}
Аннотация. Цель исследования - определить особенности категории полидискурсивности как одного из способов реализации категории интерсемиотичности в прессе Германии и США. Категория полидискурсивности рассматривается в статье как совокупность нескольких дискурсов в рамках одного текста. Особое внимание уделяется разновидностям полидискурсивности, гармонично дополняющим друг друга в газетных статьях, относящихся к прессе Германии и США. Научная новизна исследования заключается в подходе к полидискурсивности с лингвокультурной точки зрения. Данная проблема мало изучена и требует дальнейшего рассмотрения. В результате исследования выявлены сходства и различия полидискурсивности в американской прессе и прессе Германии. Подчёркивается важная роль гиперссылок как элемента полидискурсивности в прессе.
\end{abstract}

\title{
EN Multi-Discursivity as Means of Intersemioticity Category Realization (by the Material of the German and American Press)
}

\author{
Kolomiytseva O. Y.
}

\begin{abstract}
The paper examines multi-discursivity as a means of the intersemioticity category realization in the German and American newspaper discourse. Multi-discursivity is considered as integrity of discursive models within a single text. Special attention is paid to analysing multi-discursive models harmoniously supplementing each other in the German and American newspaper discourse. Scientific originality of the research involves the linguo-cultural approach to analysing the multi-discursivity phenomenon. This problem is poorly investigated and requires further study. The research findings are as follows: the author identifies specificity of the multi-discursivity category realization in the German and American newspaper discourse. The role of hyperlinks as a component of multimodal newspaper discourse is emphasized.
\end{abstract}

\section{Введение}

Актуальность темы исследования обусловлена тем, что дискурс является одним из центральных концептов современного гуманитарного знания. Вокруг него ведутся дискуссии в разных научных дисциплинах: философии, культурологии, истории, социологии, психологии, лингвистике, что свидетельствует о многомерности и многоаспектности этого понятия, невозможности его сведения к какой-либо одной модели. Активная разработка этой категории отражает сдвиг в научной парадигме, а именно: переход к междисциплинарному исследованию функционирования языка в разных областях жизни языкового сообщества, взаимодействия языковой и социальной практик, роли языка в развитии и становлении субъекта и языкового коллектива [1, с. 7].

Для достижения указанной цели исследования необходимо решить следующие задачи: выявить характерные черты полидискурсивности как способа реализации категории интерсемиотичности; определить составные элементы полидискурсивности; сравнить функционирование элементов полидискурсивности в прессе Германии и США.

Для решения перечисленных задач в исследовании использовались следующие методы: метод дискурсанализа, сопоставительный анализ.

Теоретической базой исследования послужили публикации Н. А. Ахреновой, Е. В. Белоглазовой, Б. Я. Мисонжникова, Е. И. Шейгал, М. А. Кожиной, Л. Филлипс, М. В. Йоргенсен, посвящённые дискурс-анализу, текстовому взаимодействию, полидискурсивности, гипертекстуальности. 
Материалом для анализа послужили следующие американские и германские интернет-издания, имеющие самый крупный тираж: USA Today, The Wall Street Journal, The New York Times, The Los Angeles Times; Frankfurter Allgemeine Zeitung, Die Zeit, Die Welt, Süddeutsche Zeitung, опубликованные с 2016 г. по 2021 г.

Практическая значимость исследования заключается в возможности использования его результатов в курсах по интерсемиотичности, полидискурсивности и дискурс-анализу.

\section{Полидискурсивность: характерные черты и составные элементы}

В исследованиях некоторых учёных дискурс определяется как система общения (коммуникативная система). Л. Филлипс и М. В. Йоргенсен определяют дискурс как особый способ общения и понимания окружающего мира (или какого-то аспекта мира) [8, с. 18]. Е. И. Шейгал понимает дискурс похожим образом как систему коммуникации, имеющую реальное и виртуальное измерения. «В реальном измерении это текущая речевая деятельность в определенном социальном пространстве, связанная с реальной жизнью... В виртуальном измерении дискурс представляет собой семиотическое пространство, включающее вербальные и невербальные знаки, а также - тезаурус прецедентных текстов» [9, с. 12-13].

В том случае, когда в одном текстовом пространстве взаимодействуют несколько дискурсов, речь идёт о полидискурсивности (полидискурсности). М. А. Кожина рассматривает полидискурсивность как особое свойство текста транслировать разные когнитивные модели, то есть соединять в себе модели различных дискурсов и трансформировать их в своей структуре, подчиняя авторским задачам. Характер дискурсивного смешения и взаимодействия можно выявить в рамках текста [5, с. 10]. В отношении художественного текста исследователь полагает, что полидискурсивность характеризует принципы создания текста и проявляется на тематическом (в выборе темы), сюжетном (во внутренней сюжетно-фабульной организации текста), концептуально-ценностном (в построении концептуальной основы текста на основе соединения/сопоставления общекультурной и авторской картины мира) и языковом (в подборе соответствующих для оформления коммуникативного замысла языковых средств) уровнях. При этом языковые маркеры полидискурсивности обозначают области тематического, жанрового, концептуального пересечения данных типов дискурсов в художественном тексте [Там же, с. 10-12].

Проще подходит к определению полидискурсивности (полидискурсности) Е. В. Белоглазова, представляя её как «переплетение различных дискурсов в единый социокультурно-обусловленный полидискурс, воспроизводящий себя в открытом множестве текстов, объединенных общей сферой применения и специфичной идеологией» [3, с. 121-122].

Полидискурсивность, несомненно, является способом реализации категории интерсемиотичности, так как несколько дискурсов (для каждого из которых характерны свои знаки, своя семиотика), объединённых в рамках одного текста, есть интерсемиотическая система. Это не противоречит мнению Л. П. Воскобойниковой, которая, рассматривая интерсемиотичность на материале художественного текста, констатирует, что интерсемиотичность реализуется в нём двояким образом: во-первых, в плане взаимодействия разных типов языковых знаков, а во-вторых, в плане взаимодействия разных социальных норм, и впервые представляет интерсемиотичность как категорию текста, настолько же значимую для понимания условий его строения и функционирования, как и связность, когезия, интеграция, завершённость, ретроспекция, проспекция, выраженность, структурность, отграниченность, интертекстуальность, гипертекстуальность, коммуникативность [4, с. 6-7].

К полидискурсивности в прессе можно отнести, во-первых, читательский комментарий и обращение автора к читателю, во-вторых, гиперссылки. Чатовый дискурс, представляющий собой диалог читателейкомментаторов, уже являет реципиенту отдельную комплексную интерсемиотическую систему, состоящую из текста (осложнённого всем спектром параграфематических средств, в том числе и синграфематических, не характерных для публицистического дискурса), фотографий и иных иллюстраций (рисунки, отрывки из комиксов и т.д.), видео- и аудиофрагментов, эмотиконов, стикеров и иных вербальных и невербальных средств. Во взаимодействии с публицистическим дискурсом чатовый дискурс образует ещё более сложную интерсемиотическую систему нового уровня.

\section{Функционирование элементов полидискурсивности в прессе Германии и США}

Читательский комментарий в настоящее время - неотъемлемая часть большинства онлайн-статей. Как справедливо замечает Б. Я. Мисонжников, «читательское мнение, будучи полифункциональным, решает важную утвердительную задачу. Читатель высказывается, как правило, на основе прочитанного материала и на основе своего предыдущего опыта, не прибегая к сложным логическим действиям. В редакции могут предположить, какую позицию займёт реципиент, и стараются с максимальным результатом использовать его выступление. В этом случае нарративная цепочка получает очень важное звено: на какое-то время читатель перестаёт быть читателем и становится автором, усиливает потенциал продуцентов комплексного медиапроизведения» [6, с. 106-107].

В прессе возможность комментирования некоторых информационных сообщений (например, заметок) ограничена, однако настоящие проблемные статьи читатель может прокомментировать. По прошествии 
некоторого времени возможность комментирования статей закрывается: “Vielen Dank für die Diskussion. Die Kommentarfunktion für den Artikel ist jetzt geschlossen” [11]. / «Большое спасибо за дискуссию. Функция комментирования статьи на данный момент закрыта».

В некоторых газетах редакция побуждает читателя к активному комментированию, создавая ему площадку для выражения собственного мнения (зачастую такой площадкой служат социальные сети, в большинстве случаев - Facebook и Twitter). Например, USA Today призывает: “Join the Nation's Conversation” [10] («Присоединяйтесь к разговору с нацией»), приглашая читателей комментировать прочитанное. Конечно, и в прессе США, и в прессе Германии существуют пользовательские правила, которым комментаторы обязаны следовать. В их перечень входят запрет на провокационные высказывания, дискриминацию кого-либо, оскорбление других читателей; уместность комментария, бережное обращение с цитатами (они не должны нарушать ничьих авторских прав, то есть не являться плагиатом); запрет на размещение в комментариях рекламы и чьих-либо личных данных и т.д.

В комментариях разворачиваются настоящие дискуссионные битвы между читателями, если комментируемая статья освещает какой-либо чувствительный социальный вопрос, комментаторы используют яркие поликодовые средства (например, эмотиконы или стикеры), чтобы произвести впечатление друг на друга и завоевать популярность (Рисунок 1).

Читатели обсуждают проблему воровства продуктов из магазинов. Как мы можем наблюдать, пользователи могут поставить «лайк» под понравившимся им комментарием, а нажав “reply”, ответить, ведя полноценный диалог (или скорее полилог) с участниками чата.

Аналогичные примеры комментариев существуют, конечно, и в прессе Германии, но их отличает гораздо более деловой и сухой стиль (отсутствие эмотиконов, особых синграфематических средств и т.д.). Немецкий читатель реагирует на информационное сообщение более взвешенно и менее эмоционально (пример из газеты Welt, реакция читателей на статью о преступлении, совершённом одним из мигрантов, подозревающемся в том, что он состоит в ИГИЛ (организация запрещена в РФ)) - подробнее см. Рисунок 2.

Здесь читателями обсуждается довольно острая тема - разрешение въезда в Германию боевиков, прошедших обучение в лагерях ИГИЛ (организация запрещена в РФ). Читатели сомневаются в «иммунной системе», проводящей политику подобной толерантности к людям, несущим потенциальную угрозу. Метафорическое наименование “Immunsystem” также является интерсемиотическим элементом, поскольку представляет собой вторичную номинацию.

Как утверждает Б. Я. Мисонжников, «в комментариях зачастую наблюдается избыточная языковая экспрессия, поскольку к этому располагает их анонимность. Высказывания носят в известной мере репликовый характер и чётко выражены интенционально. Они легко выстраиваются в систему, образуя единый, хотя формально и мозаичный, дискурс, который становится контрарным элементом по отношению к первоначальному, провоцирующему полемику тексту. Коммуникативным компонентом здесь выступает “репликовый шаг” “единица диалогического взаимодействия партнёров” [6, с. 108]. Из этого можно сделать вывод о том, что взаимодействие текста информационного сообения и комментариев является взаимной интеграцией двух дискурсов: публицистического и дискурса комментариев, о котором и говорит Б. Я. Мисонжников. Взаимоотношения этих двух разных дискурсов мы и рассматриваем как интерсемиотичные.

В американской прессе зарегистрированные комментаторы зачастую организованы в полноценную социальную сеть (Рисунок 3).

В комментируемой статье речь идёт об американце Кайле Уильямсе, бывшем спортсмене, осуждённом за нанесение ножевых ранений нескольким лицам, попытку изнасилования и несколько похожих преступлений в разных штатах. Из дискурса-чата видно, что его участники совершенно не стесняются в выражениях, делая выпады в адрес главного фигуранта статьи и друг друга. Используемая лексика является весьма экспрессивной, а зачастую - обсценной (sub-animal - «недоживотное», unevolved scum - «недоразвитый подонок», idiot «идиот», racist cretin - «расистский кретин»). Очевидно, что в публицистическом дискурсе подобные номинации не могут быть использованы, в отличие от дискурса комментаторов, однако располагаются упомянутые комментарии непосредственно под статьёй, то есть здесь присутствует полидискурсивность.

В комментариях к статьям германской прессы также попадаются включения из соцсетей. Следующий пример иллюстрирует статью из газеты Welt, где речь идёт о харрасменте моделей (Рисунок 4).

Немецкий фотограф Тимур Эмек, обладающий немалой известностью, требовал от моделей по 2000 евро за сессию, либо он снимет их бесплатно в обнажённом виде. Статья сопровождается несколькими фрагментарными включениями из сети Instagram, в которых возмущённые пользователи высказывают Эмеку своё негодование (причём на английском языке). Включение фрагмента на английском языке в статью на немецком языке может быть объяснено тем фактом, что большинство людей во всём мире с ним знакомо. Автор статьи абсолютно уверен в том, что читатели без труда разберутся, о чём идёт речь. По нашему мнению, если бы журналист хотел привести в качестве примера отрывок на каком-либо ином языке, он бы поместил ниже перевод такого фрагмента на немецкий язык. Слова и выражения, используемые комментаторами для характеристики Тимура Эмека и фотографов, ведущих себя подобным образом, как и в американской прессе, имеют негативную окраску (sleazy - «озабоченный», clout-abusing - «подрывающий престиж, абьюзивный», crotch-grabbing - здесь «омерзительный»). Такой вокабуляр (тем более на английском языке) не типичен для публицистического дискурса Германии, характеризующегося высоким уровнем авторской самоцензуры и отсутствием избыточной экспрессии. 
Помимо перечисленного, информационные сообщения могут сопровождаться обращениями автора/ редактора к читателю. Это создаёт ситуацию, в которой происходит интеракция «газета - читатель» (Рисунок 5). Такие обращения могут быть краткими и формальными (USA Today).

С помощью повелительного наклонения (get alerted to the latest stories - «получайте информацию о последних новостях») редактор повышает апеллятивность информационного сообщения, приглашая реципиента вступить в контакт с газетой.

Такие обращения в прессе Германии могут содержать подробный текст с указаниями того, как следует действовать в определённой ситуации (Рисунок 6).

Таким любопытным «посланием к читателю» сопровождалось информационное сообщение в газете Frankfurter Allgemeine Zeitung о самоубийстве пресловутого Джефри Эпштейна, фигуранта массовых преступлений на сексуальной почве. Это обращение призвано помочь человеку, у которого появились суицидальные мысли, преодолеть их; его дискурс имеет лишь косвенные точки пересечения с основной статьёй. Следует отметить, что для указанного дискурса также характерна апеллятивность (Wenn Sie daran denken, sich das Leben zu nehmen, versuchen Sie mit anderen Menschen darüber zu sprechen - «Если Вас одолевают мысли о самоубийстве, постарайтесь поговорить об этом с другими людьми»). Многократное повторение местоимения «Вы - Sie» обладает высокой степенью персуазивности и призвано оказать давление на читателя, убедив его отказаться от суицидальных мыслей. Далее в тексте обращения можно наблюдать и суггестивные средства, влияющие на реципиента имплицитно: “Die Telefonseelsorge ist anonym, kostenlos und rund um die Uhr erreichbar” - «Tелефон доверия анонимный, бесплатный и доступен в любое время суток». Тем самым редактор усиливает посыл сообщения, применяя манипулятивные технологии, сходные с технологиями публицистического дискурса.

Помимо взаимодействия «автор - читатель», одним из элементов полидискурсивности является гиперссылка. Гиперссылка - это не только элемент гипертекстуальности, но и элемент интерсемиотичности, так как всегда отсылает к иному дискурсу. Это не противоречит точке зрения Н. А. Ахреновой, утверждающей, что «важным является тот факт, что гипертекст активно использует различные знаковые системы, образуя тем самым своего рода текст-гибрид, называемый в лингвистике креолизованным, т.е. текст, фактура которого состоит из двух неоднородных частей: вербальной и невербальной» [2, с. 4]. Понятие интерсемиотичности всё более замещает понятие «креолизованного текста», являясь гораздо более широким и всеобъемлющим. Н. А. Ахренова также выделяет важные характеристики гипертекста: 1) гипертекстуальность; 2) интерактивность (в Интернете всё связано, создано на основе законов обратной связи, когда информация получается, обрабатывается, и пользователь мгновенно получает отклик на свой запрос или действие); 3) виртуальность («эфемерность», «нематериальность» пространства, в котором существует интернет-дискурс, которое часто противопоставляется пространству реальному); 4) анонимность, особенно характерная для начальных годов публицистическом онлайн-дискурсе, следовательно, позволяют считать его интерсемиотической системой.

Любая гиперссылка - элемент интерсемиотичности. Многие интернет-ресурсы приводят такую классификацию гиперссылок: 1) внешние и внутренние гиперссылки; 2) текстовые и графические гиперссылки. Подробную классификацию гиперссылок приводит В. Н. Сурина, ссылаясь на исследования Е. В. Зыковой:

1) графически маркированные и графически немаркированные;

2) внутритекстовые и вынесенные за пределы вербальной части текста;

3) релевантные, нерелевантные и частично релевантные гиперссылки;

4) продуктивные и непродуктивные с позиции их навигационных особенностей;

5) адаптированные и неадаптированные гиперссылки [7, с. 121].

Применительно к исследуемым нами статьям мы придерживаемся следующей классификации гиперссылок, созданной на основании двух вышеперечисленных:

1) текстовые и текстово-графические гиперссылки;

2) внешние и внутренние гиперссылки. Внешние гиперссылки отсылают пользователя к иным веб-объектам (сайтам). Это могут быть другие газеты, нормативные акты, архивные документы, рекламные сайты и т.д. Внутренние же гиперссылки отсылают к статьям того же онлайн-издания, где они размещены;

3) внутритекстовые и вынесенные за пределы вербальной части текста.

Текстовые гиперссылки выражены вербально внутри исходного текста статьи и маркированы подчёркиванием, цветом, жирным шрифтом и т.д. (Рисунок 7).

Гиперссылки в данном случае выделены другим цветом и отсылают к статьям на ту же тематику, что и исходная статья, однако это иные статьи, написанные другими авторами с использованием иных лингвостилистических средств, то есть полидискурсивность здесь также присутствует. Сочетание “реople killed” проходит лейтмотивом через весь текст, представляя собой нелингвистический контекст. Именно отношение текста к нелингвистическому контексту является интерсемиотическим отношением.

Любопытным представляется тот факт, что в прессе Германии гораздо меньше текстовых гиперссылок, иногда встречаются статьи вообще без них, что для американской прессы является редким случаем. Пример такой статьи из газеты Frankfurter Allgemeine Zeitung представлен на Рисунке 8.

Итак, во всём тексте статьи нами не было обнаружено ни одной текстовой гиперссылки, тогда как справа видна текстово-графическая гиперссылка с рекламной тематикой. В остальном информационное сообщение представляет собой однородный текст, в котором речь идёт о судебном процессе, инициированном из-за убийства. Полидискурсивность в данном случае достигается взаимодействием публицистического и юридического дискурсов. 


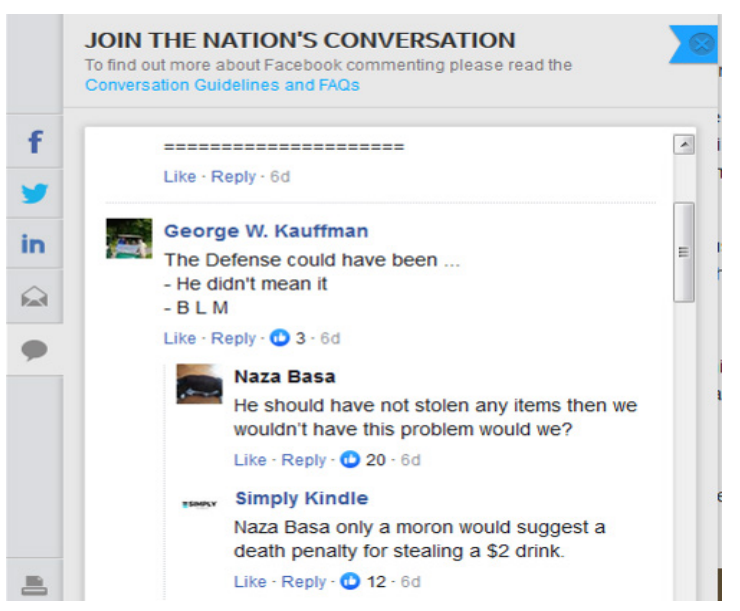

Рисунок 1. Читательский комментарий в американской прессе

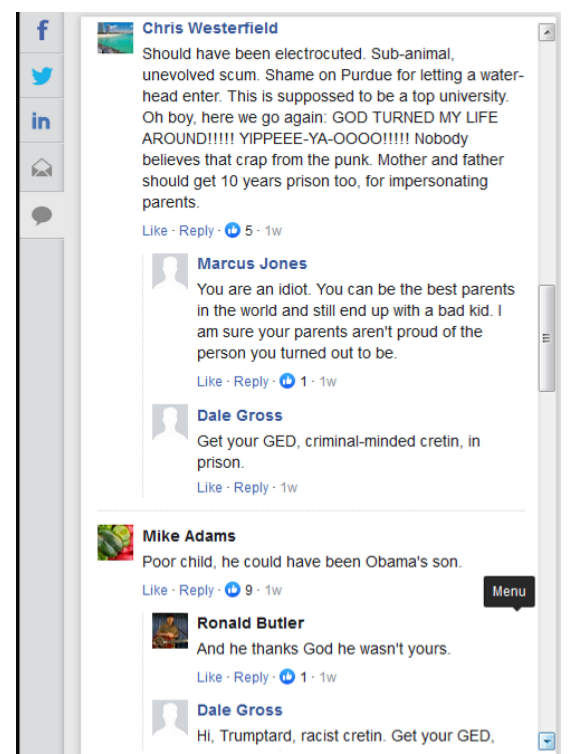

Рисунок 3. Социальная сеть комментаторов в прессе США

\section{Get the News Alerts newsletter in your inbox.}

Get alerted to the latest stories to stay on top of the news.

Delivery: Varies

Your Email

Рисунок 5. Обращение редактора к читателю в прессе США
AxelK.

vor 2 Johren

".. über keine geeignete Unterkunft für solche Gefährder verfüge." Dann sollte man ungeeignete nutzbar machen. Armes Deutschland, dass mit Samthandschuhen seine Pflichten vernachlässigt. Und - warum lässt man IS-Söldner überhaupt wieder einreisen? Wenn das Immunsystem eines Organismus so fehlerhaft ist, wird er bald erliegen.

Poseidon

vor 2 Johren

Das ist das Ergebnis einer falschen Einwanderungspolitik, politischer Verblendung und von die Schuld von Aktivisten, bei denen ein mögliches Opfer politischer Verfolgung einen höheren Wert hat als die künftigen Opfer seiner Straftaten.

Рисунок 2. Читательский комментарий в прессе Германии

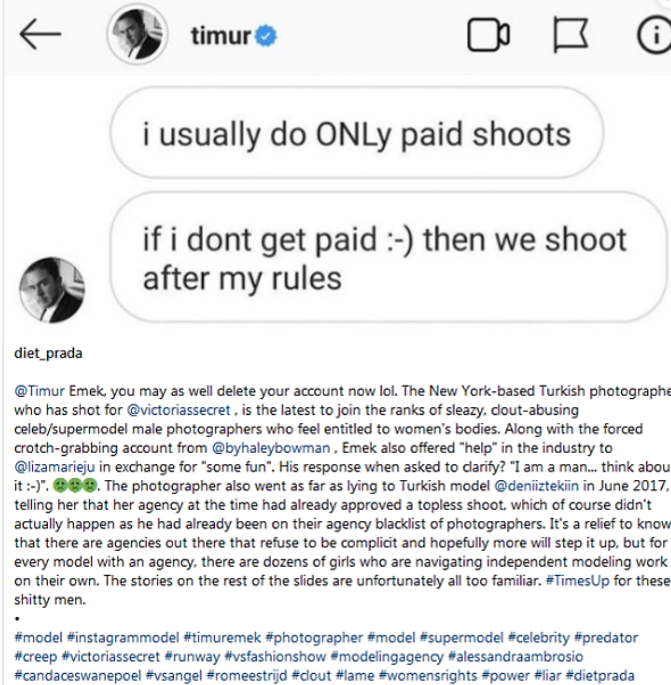

Рисунок 4. Социальная сеть комментаторов в прессе Германии

\section{Hilfe bei Suizidgedanken}

Wenn Sie daran denken, sich das Leben zu nehmen, versuchen Sie, mit anderen Menschen darüber zu sprechen. Es gibt eine Vielzahl von Hilfsangeboten, bei denen Sie - auch anonym - mit anderen Menschen über Ihre Gedanken sprechen können.

Das geht telefonisch, im Chat, per Mail oder persönlich.

Die Telefonseelsorge ist anonym, kostenlos und rund um die Uhr erreichbar. Die Telefonnummern sind $0800 / 1110111$ und $0800 / 1110222$. Der Anruf bei der Telefonseelsorge ist nicht nur kostenfrei, er taucht auch nicht auf der Telefonrechnung auf, ebenso nicht im Einzelverbindungsnachweis.

Ebenfalls von der Telefonseelsorge kommt das Angebot eines Hilfe-Chats. Die Anmeldung erfolgt auf der Webseite der Telefonseelsorge. Den Chatraum kann man auch ohne vereinbarten Termin betreten, mit etwas Glück ist ein Berater frei. In jedem Fall klappt es mit einem gebuchten Termin.

Das dritte Angebot der Telefonseelsorge ist die Möglichkeit der E-Mail-Beratung. Auf der Seite der Telefonseelsorge melden Sie sich an und können Ihre Nachrichten schreiben und Antworten der Berater lesen. So taucht der E-MailVerkehr nicht in Ihren normalen Postfächern auf.

Рисунок 6. Обращение редактора к читателю в прессе Германии 


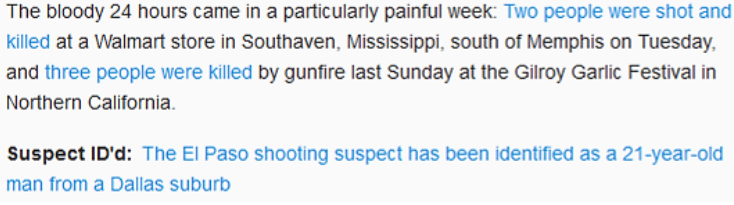

Рисунок 7. Текстовые гиперссылки в прессе США ach 18 Verhandlungstagen geht es auf einmal unerwartet schnell: Schon am Donnerstag und damit wenige Tage vor dem ersten Jahrestag des gewaltsamen Todes des Chemnitzers Daniel H. soll das Urteil gegen einen der zwei Tatverdächtigen gesprochen werden. Ursprünglich waren Termine bis zum 29. Oktober vorgesehen.

Das Finale läutete am Montag Staatsanwalt Stephan Butzkies ein. Der Anklagevertreter beantragte in seinem Plädoyer eine Gesamthaftstrafe wegen Totschlags und gefährlicher Körperverletzung von zehn Jahren für den Angeklagten. Die Höchststrafe bei Totschlag beträgt 15 Jahre. Vor der erwarteten Urteilsverkündung halten die drei Nebenklagevertreter sowie die Verteidigung am kommenden Donnerstag ihre Schlussvorträge. Zudem darf der Angeklagte, der während des gesamten Prozesses zu den Tatvorwürfen geschwiegen hat, sein letztes Wort sprechen.

Рисунок 8. Отсутствие текстовых гиперссылок в статье германской прессы

Чисто графических ссылок в прессе не было выявлено. Текстово-графических гиперссылок, представляющих собой иконический элемент (рисунок, фотографию и т.д.) в сочетании с текстом, было выявлено незначительное количество. В основном это были «кликабельные» фотографии с надписями рядом. Интересно, что в данном случае не все гиперссылки соотносились по смыслу с текстом статьи.

Относительно внешних и внутренних гиперссылок следует отметить, что и первые, и вторые встречались одинаково часто и в германской прессе, и в американской.

\section{Заключение}

Таким образом, мы приходим к следующим выводам. Полидискурсивность является способом реализации категории интерсемиотичности, так как несколько дискурсов, объединённых в одной газетной статье, представляют собой интерсемиотическую систему. Элементами полидискурсивности в прессе Германии и США являются читательский комментарий и гиперссылки.

Для читательского комментария характерны следующие языковые особенности: используемая лексика является весьма экспрессивной, а в некоторых случаях - обсценной. Такая лексика нетипична для публицистического дискурса, характеризующегося высоким уровнем авторской самоцензуры и отсутствием избыточной экспрессии. При обращении автора или редактора к читателю используется весь спектр персуазивных и суггестивных средств, влияющих на реципиента (императив, повторение местоимения «Вы»).

Полидискурсивность в случае гиперссылок достигается взаимодействием публицистического и какого-либо иного дискурса (например, юридического) или с помощью отношения текста к нелингвистическому контексту.

В то время как в прессе США читательские комментарии выглядят живо и ярко, в прессе Германии их отличает более деловой и сухой стиль, что говорит о более взвешенном и менее эмоциональном восприятии информационных сообщений немцами.

Перспективы дальнейшего исследования проблемы мы видим в более детальном изучении имплицитных средств реализации категории интерсемиотичности в прессе (вторичные и третичные номинации, прецедентность). Также интерес представляет анализ корреляций вербального и невербального компонентов в интерсемиотической системе.

\section{Источники | References}

1. Андреева В. А. Литературный нарратив: текст и дискурс. СПб.: Норма, 2006. 182 с.

2. Ахренова Н. А. Интернет-дискурс как гипертекст // Вестник Московского государственного областного университета. 2016. № 3. С. 1-12.

3. Белоглазова Е. В. Интердискурс и полидискурс: соотношение понятий // Стил: международный научный журнал. 2008. Т. 7. С. 121-131.

4. Воскобойникова Л. П. Интерсемиотичность как фактор формирования смысловой структуры текста (на материале французских художественных текстов): автореф. дисс. ... к. филол. н. М., 2014. 29 с.

5. Кожина М. А. Языковые маркеры полидискурсивности в художественном тексте (на материале романа Ф. М. Достоевского «Преступление и наказание»): автореф. дисс. ... к. филол. н. Томск, 2012. 24 с.

6. Мисонжников Б. Я. Читательский комментарий в сетевой версии газеты как метатекст (на материале публикаций немецкого таблоида “Bild”) // Учёные записки Забайкальского государственного университета. 2015. № 2 (61). С. 106-110.

7. Сурина В. Н. Классификационные параметры гиперссылок // Вестник Челябинского государственного университета. 2013. № 35 (326). С. 120-122.

8. Филлипс Л., Йоргенсен М. В. Дискурс-анализ. Теория и метод / пер. с англ. и науч. ред. А. А. Киселёвой. Изд-е 2-е, испр. Х.: Гуманит. центр, 2008. 352 с. 
9. Шейгал Е. И. Семиотика политического дискурса. М.: Гнозис, 2004. 326 с.

10. USA Today [Электронный ресурс]. 2021. June 25. URL: https://www.usatoday.com/story/news/politics/2021/06/25/ senate-confirms-first-female-national-counterterrorism-center-director/5351365001/(дата обращения: 25.06.2021).

11. Welt [Электронный ресурс]. 2016. November 23. URL: https://www.welt.de/wirtschaft/webwelt/article159690903/ Neue-Funktionen-fuer-die-Welt-Community.html (дата обращения: 23.01.2021).

\section{Информация об авторах | Author information}

RU Коломийцева Ольга Юрьевна ${ }^{1}$, к. филол. н.

${ }^{1}$ Самарский университет государственного управления «Международный институт рынка»

EN Kolomiytseva Olga Yuryevna ${ }^{1}, \mathrm{PhD}$

${ }^{1}$ Samara University of Public Administration “International Market Institute”

${ }^{1}$ olga.kolomiytseva@mail.ru

\section{Информация о статье | About this article}

Дата поступления рукописи (received): 24.06.2021; опубликовано (published): 15.09.2021.

Ключевые слова (keywords): дискурс; полидискурсивность; интерсемиотичность; гиперссылка; комментарий; discourse; multi-discursivity; intersemioticity; hyperlink; commentary. 